\title{
Revivendo experiências: em foco a leitura em comunidades
}

Marlene Edite Pereira Rezende

\begin{abstract}
Bibliotecária, especialista em Literatura Infantil e Juvenil. Ex-diretora de Leitura e Informação da Fundação Municipal de Cultura.
\end{abstract}

http://dx.doi.org/10.1590/1981-5344/2281

Este artigo teve como objetivo recuperar, de forma destacada, duas experiências de trabalho de extensão na UFMG: o carro-biblioteca da ECI UUFMG e a implantação das Bibliotecas Públicas e Biblioteca Móvel do COLTECIUFMG. A estas experiências somaram-se ainda as informações sobre as atividades de extensão, através de Carros-Biblioteca, realizadas no âmbito da Biblioteca Pública Estadual Luiz de Bessa e pelo SESC. Revendo estas experiências torna-se patente a importância destas ações para as comunidades, mas, revelam-se também as dificuldades/limitações para a continuidade e ampliação destes serviços que são de caráter significativo para a população. Destaca-se também que os projetos visam permitir o acesso à leitura em comunidades com carências socioculturais, mas, demostram, de forma crítica, a realidade e os desafios dos municípios de Caparaó e Alto Caparaó na administração e manutenção das bibliotecas lá instaladas. Argumenta-se ainda, como aspecto significativo, a necessidade de articulação das comunidades, de forma a reivindicarem junto aos gestores públicos $o$ atendimento aos direitos da população.

Palavras-chave: Extensão bibliotecária. Bibliotecas Públicas - comunidades rurais.

\section{Revivingi experiences: focus on reading in communities}

This article aims to retrieve, prominently, two experiences of short duration academic work at UFMG: mobile carlibrary at ECI I UFMG and the implementation of the Public Libraries and the Mobile Library COLTEC I UFMG. To 
these experiences still added up the information on the extension activities through mobile car-library, held within the State Public Library Luiz de Bessa and the SESC. By reviewing these experiences, it becomes evident the importance of these actions for the communities, but also reveals the difficulties / limitations to the continuation and expansion of these services which are of a significant nature to the population. Yet, it highlights that the projects aimto enable access to reading in communities with socio-cultural needs, and on the other sideit demonstrates, critically, the reality and challenges of Caparaóand Alto Caparaó municipalitiesin the administration and maintenance of libraries installed. Yet it is argued, as a significant aspect, the need to articulate the communities, in order to claim together with public service managers the rights of the population.

Keywords: Librarian extension. Public Libraries - Rural communities.

Recebido em23.11.2014 Aceito em 24.11.2014

\section{Introdução}

A proposta de apresentação do tema "Biblioteca pública: significado, importância social e desafios na contemporaneidade" durante o Seminário "A Biblioteca Pública no século XXI: lugar social, atuação política e estratégias de mobilização cultural" propiciou a oportunidade de resgatar e falar de duas experiências de programas de extensão da UFMG bem como das atividades do Sesc e da Biblioteca Pública Estadual Luiz de Bessa.

No que se refere à extensão da UFMG vale destacar o primeiro deles: o "Carro-Biblioteca: frente de leitura", da Escola de Ciência da Informação e o segundo: o projeto "Educação ambiental em Caparaó: proposta" de construção de uma comunidade de aprendizagem", do COLTEC. A estas experiências optou-se também por destacar as atividades de extensão realizadas pelo carro-biblioteca do Sesc e o da Biblioteca Pública Estadual Luiz de Bessa, de forma a evidenciar a atuação também destes serviços, com vistas a demonstrar a cobertura dos carrosbibliotecas no contexto da Região Metropolitana de Belo Horizonte. As experiências relatadas refletem a importância da extensão enquanto propulsora do desenvolvimento cultural, em comunidades que dispõem de restritas oportunidades de participar de atividades socioculturais. Mostra também que a leitura pode contribuir para o desenvolvimento humano e, evidencia o quanto os gestores públicos desconhecem e têm pouca sensibilidade para investimentos na área cultural. 
$\mathrm{Na}$ realidade compreendemos que é papel do governo (federal, estadual e municipal) garantir que serviços públicos de biblioteca sejam priorizados e, possibilitar ao cidadão o direito de reivindicar bons serviços. Os dois trabalhos de extensão aqui descritos e desenvolvidos na UFMG, demonstram investimento e compromisso na formação de leitores, ao manter os serviços do carro-biblioteca e apoiar a implantação das bibliotecas públicas nos municípios de Alto Caparaó e Caparaó, localizados na zona da mata mineira. Assim, a universidade participa de forma tríplice quando possibilita que o ensino, a pesquisa e a extensão sejam objeto de uma mesma ação. Vale também apontar a relevância e a contribuição dos serviços de extensão do Sesc e da Biblioteca Pública Luiz de Bessa na medida em que estas ações ampliam a atuação extensionista no contexto da região metropolitana de Belo Horizonte.

\section{Onde estão os carros-biblioteca?}

Propiciar o debate sobre o Carro-Biblioteca da UFMG e outros que foram criados pelo extinto INL - Instituto Nacional do Livro surgiu como possibilidade de colocar em discussão, no Seminário, a sobrevivência de programas que apesar das mudanças de planos e políticas de governo continuaram suas atividades. Desta forma, a primeira tentativa foi buscar informações na Biblioteca Nacional, instituição essa, que incorporou as funções do INL. A informação, segundo a Coordenação Geral, é que o Sistema Nacional de Bibliotecas Públicas, ainda, não tem estes dados sistematizados, o que impossibilita afirmar quais instituições ainda mantém o serviço de carro-biblioteca criado pelo INL. Em termos da UFMG, o convênio teve início em 1973 com o fornecimento do veículo, acervo e contratação de bolsistas pelo INL e a coordenação do serviço, abastecimento do combustível e disponibilização do motorista a cargo da UFMG.

É oportuno indicar que para apresentar este trabalho restringiu-se o campo de atuação em Minas Gerais. Os dados obtidos e apresentados a seguir representam o esforço de um levantamento realizado pelo Sistema Estadual de Bibliotecas Públicas, da Superintendência de Bibliotecas Públicas do Estado. Entretanto, ressalta-seque o quadro indica a relação dos municípios que possuem serviço de extensão bibliotecária (carrobiblioteca), mas não há informação se algum deles foi originado de convênio com o INL; apenas o da Biblioteca Pública Estadual Luiz de Bessa que se iniciou em 1960, conforme consta em seu histórico.

Vale ainda apontar as evidencias da importância das ações de extensão na democratização e acesso à leitura realizadas em comunidades periféricas; entretanto o número é inexpressivo se considerados os 851 municípios, em Minas e a quantidade de bairros em Belo Horizonte e região metropolitana. Por outro lado à falta de sistematização de dados no Sistema Nacional dificulta sua análise, em relação ao custo $X$ benefício do programa, como base para implantação em outras localidades e comparálos a outras modalidades de biblioteca. 


\begin{tabular}{|c|c|c|}
\hline Região de Minas Gerais & Município & Biblioteca Pública Municipal \\
\hline \multirow{3}{*}{ Alto Paranaíba } & Araxá & Viriato Correia \\
\hline & Ibiá & Vicente Costa \\
\hline & Ibiá & Prof. Eduardo A. Castro \\
\hline \multirow{2}{*}{ Central } & Belo Horizonte & Estadual Luiz de Bessa (*) \\
\hline & Contagem & Dr. Edson Diniz (*) \\
\hline Centro-oeste & Perdões & Francisco A. Pereira \\
\hline Jequitinhonha & Cachoeira do Pajeú & Pública e Espaço Cultural Jailson Viana \\
\hline Mata & Ponte Nova & Miguel Valentino Lana \\
\hline \multirow{2}{*}{ Mucuri } & Bertópolis & Bertópolis (*) \\
\hline & Santa Helena de Minas & Etelvina T. de Jesus \\
\hline Norte & Matias Cardoso & Pública Comunitária Brasilino F. Santos \\
\hline \multirow{3}{*}{ Rio doce } & Carmésia & Educador Paulo Freire \\
\hline & Ipatinga & Zumbi dos Palmares \\
\hline & Tumiritinga & José Ferreira de Assis (*) \\
\hline \multirow{5}{*}{ Sul } & Andradas & Délia Maria R. Souza \\
\hline & Brazápolis & Brazápolis(*) \\
\hline & Cachoeira de Minas & Pedro Serafim Gomes \\
\hline & Extrema & Prudência C. Pereira \\
\hline & Poços de Caldas & Centenário (*) \\
\hline Triângulo & Uberlândia & Juscelino K. Oliveira $(*)$ \\
\hline
\end{tabular}

$\left(^{*}\right)$ Bibliotecas que possuem também serviço de caixa e ou malas de leitura.

\section{A extensão na Biblioteca Pública Estadual}

A Biblioteca Pública Estadual Luiz de Bessa mantém serviços de carro-biblioteca e caixa estante com atendimento a várias comunidades em Belo Horizonte e Região Metropolitana. O carro-biblioteca, inaugurado em 1960, tem em seus objetivos levar informação e cultura aos bairros da Região Metropolitana de Belo Horizonte que não possuem biblioteca ou equipamentos culturais e valorizar a leitura como direito do cidadão. Com atendimento semanal visitando, atualmente, os seguintes bairros da Capital:

\begin{tabular}{|l|l|}
\hline Capitão Eduardo & Segunda-feira \\
\hline Diamante / Nova Pampulha & Terça-feira (alterna as semanas) \\
\hline Vale do Jatobá & Quarta-feira \\
\hline Conjunto Ribeiro de Abreu & Quinta-feira \\
\hline Minas Caixa & Sexta-feira \\
\hline
\end{tabular}

\section{A extensão na Ciência da Informação da UFMG}

com ele"

"Um bom livro é aquele que a gente entende, gosta e aprende

(frase de Cristiano Flávio, leitor do Carro-Biblioteca da UFMG).

O conceito é o mesmo. A sua forma pode variar assim como os nomes para sua identificação: carro-biblioteca/biblioteca volante / biblioteca itinerante/biblioteca móvel/biblioteca ambulante. Concorrem também na modalidade de extensão bibliotecária as caixas estantes muito usadas em programas de incentivo à leitura, cujo objetivo é democratizar 
e facilitar o acesso à leitura e informação em locais distantes dos centros urbanos.

A biblioteca que vai ao leitor, é assim a forma prazerosa de falar do carro- biblioteca, onde trabalhei onze dos vinte anos que estive na universidade. Ele é referência para aqueles que tiveram oportunidade de atuar, seja aluno, bibliotecário ou professor. Muitos dos estagiários, hoje profissionais, que passaram pela experiência e trabalho nas comunidades reconhecem e valorizam a oportunidade.

A importância do Programa pode ser resgatada pela fala dos seus usuários, transcritas a seguir: ${ }^{1}$

"Importante demais, as mães não têm condições de comprar livros e com o carro, toda semana, as crianças têm oportunidade de conhecer novas estórias". (Barragem Santa Lúcia)

"Com o carro a gente pode ter livros, ficar atualizadas com as revistas de música, nós gostamos muito de música, e não temos dinheiro para comprar essas revistas". (Sarzedo)

"Pensei: esse povo não podia ter feito isso com a gente, eu doida para ler, sem livro, sem dinheiro, biblioteca comunitária de férias, horrível. Carro traz divertimento, cultura, livro é cultura, e de graça" (Lindéia)

"Carro é importante para estimular a leitura, muda a cabeça das pessoas, faz com que elas entendam aquilo que elas não sabiam ou não queriam entender, principalmente a leitura subversiva". (Sarzedo)

"A gente se identifica com os livros e os personagens. Ele desperta o interesse em toda a família: pai, mãe, filhos". (Lindéia)

"Livro é bom para a mende, principalmente quanto a gente tá com problemas". (Santa Luzia)

Assim, trabalhar com várias comunidades foi gratificante. No início foi Sarzedo, Ibirité, Santa Luzia, Raposos e Lindéia. Ibirité e Raposos foram substituídos por Barragem Santa Lúcia e São Benedito. Com a entrada em outras comunidades os desafios permanecem, à medida que a aproximação de novos leitores exige o desenvolvimento de estratégias para conhecer e observar suas vivências, muitos deles nunca entraram em uma biblioteca. É no carro que acontece suas primeiras experiências de leitura.

Na realidade o Carro-Biblioteca é o segundo mais antigo programa de extensão da UFMG, o que vem garantindo o apoio da instituição, em função dos resultados apresentados. Por vários anos participou da programação no Festival de Inverno e Jornada Cultural, em cidades como:

\footnotetext{
${ }^{1}$ Depoimentos dos usuários das comunidades atendidas pelo Projeto Carro Biblioteca.
} 
Ouro Preto, São João Del Rey, Diamantina, Poços de Caldas, Caparaó, Cataguazes, o que evidencia sua capacidade de aglutinar pessoas em suas ações de leitura. Em vários desses momentos foram realizadas ações conjuntas, envolvendo equipes de teatro, cinema, literatura e os frequentes convites para participar de atividades culturais em escolas, ruas de lazer, feiras e exposições enriqueceram suas experiências.

A crescente demanda de leitores exigiu maior capacidade de atendimento o que motivou a substituição da Kombi por um micro-ônibus. Em termos mais recente a aquisição de um ônibus, ampliando as funções do carro-biblioteca, incorporando ainda em seu espaço um telecentro, com seis computadores, para atender as comunidades.

\section{A extensão no SESC/MG}

Outra instituição em destaque na atividade é o SESC que adota uma metodologia de ação por meio de suas Unidades Volantes. A interiorização das atividades desde a década de sessenta, visa atender locais onde não existem unidades fixas.

Consta no histórico que a instituição iniciou suas atividades com a Unidade Volante de Medicina Preventiva. Posteriormente, foram criados novos serviços com Caminhões de Recreação e Lazer e de Biblioteca. Cada Unidade é equipada para desenvolver as atividades/serviços em suas áreas específicas, que se complementam com a realização de oficinas, gincanas, campanhas e várias atividades socioculturais. O quadro apresentado lista os bairros e municípios atendidos pelo Bibliosesc, de forma quinzenal, o que amplia o número de comunidades em Belo Horizonte e região metropolitana que contam com serviços de biblioteca móvel.

\begin{tabular}{|l|l|}
\multicolumn{1}{|c|}{$\begin{array}{c}\text { Região Metropolitana de } \\
\text { Belo Horizonte }\end{array}$} & Bairro de atendimento \\
\hline São José da Lapa & Dom Pedro I \\
\hline Rio Acima & Jatobá \\
\hline Betim & Laranjeiras \\
\hline Ribeirão das Neves & Rosa Neves \\
\hline Contagem & Jardim Laguna \\
\hline Vespasiano & Morro Alto \\
\hline Sabará & N. Senhora de Fátima \\
\hline Santa Luzia & Palmital \\
\hline & \\
\hline Regional Norte & \\
\hline Regional Centro Sul & São Paulo \\
\hline Regional Venda Nova & Aglomerado da Serra \\
\hline Regional Nordeste & Jardim Leblon \\
\hline Regional Noroeste & Universitário \\
\hline Regional Noroeste & Santo André \\
\hline Regional Oeste & Padre Eustáquio \\
\hline Regional Leste & Nova Cintra \\
\hline & Vera Cruz \\
\hline
\end{tabular}

Há também uma modalidade de ação, realizada pelo SESC, com objetivo de incentivo a leitura, de forma itinerante com o propósito de atender o interior de Minas, numa escala quinzenal. O retorno só é possível com formalização de pedido pelo município, o que tem acontecido de maneira frequente segundo seus coordenadores. 
Assim, ao analisar os dados apresentados evidenciam-se o quanto essa modalidade de serviço de biblioteca é importante, enquanto meio de democratização da leitura e informação, à medida que aproxima de pessoas que teve pouca ou nenhuma oportunidade de manusear um livro ou frequentar biblioteca. A estratégia de exposição do acervo, nas prateleiras, ao alcance das mãos mostra que o acesso é livre, basta desejá-lo. É importante também que encontre ali pessoas que conheça o acervo, goste de ler e transmita confiança ao leitor em processo de formação. A formalização de um cronograma, que permita uma frequência regular, e a interação com a comunidade local é sem dúvida fundamental para fortalecer as ações e garantir eficácia aos objetivos do programa.

\section{Serviços de carro-biblioteca: dimensões de atuação}

Há vários registros sobre o Carro-Biblioteca com depoimentos de leitores e de seu significado na vida deles. Em 2012, a edição do livro "O carro-biblioteca da ECI/UFMG" mostra em capítulos o resultado desse programa de extensão que tem muitas "histórias para contar", no sentido pleno que a expressão permite.

Constata-se assim o reconhecimento daqueles que descobriram nos livros um momento de prazer; aqueles que procuram textos que dão suporte às telenovelas, ao teatro; os que descobriram a poesia ao ler Carlos Drummond, Mário Quintana, Adélia Prado, Cecília Meireles, Vinícius de Moraes, Cora Coralina. Os muitos que são atraídos pelos relatos de viagem, pelas biografias principalmente as de pessoas famosas. Leitores que iniciaram o processo de leitura descobrindo os contos e as crônicas, para depois passarem aos grandes romances. Sem falar do público infantil onde a preferência recai sobre os contos de fadas, depois aparecem os contos de assombração, de terror e aí seguem no mundo mágico entre a fantasia e o real. Aqueles que vão ao carro a procura de uma resposta a uma pesquisa encomendada, também encontram seu espaço enquanto leitor. A identificação com a leitura de quadrinhos como: O Pato Donald, o trio comandado por Cascão, Cebolinha e Mônica, que muito contribuem na formação do leitor e por longo tempo foi motivo de debate entre professores e agentes de leitura.

É fundamental para a história da leitura em nosso país, a elaboração de estudos para sistematização dos dados, por estado, sobre os programas carro-biblioteca, criados pelo extinto INL e incorporado à Fundação Biblioteca Nacional, visando não só ter uma compreensão global da atuação dos programas no País, mas de maneira fundamental estabelecer marcos para uma política de ação que possibilite atender a multiplicidade de realidades constitutivas do País. 


\section{Bibliotecas Públicas: um momento de reflexão}

Dando continuidade a este resgate de vivências, foi oportuno retomar a experiência de Caparaó, Minas Gerais, no que se refere ao processo de implantação das bibliotecas públicas naquele contexto.

Entretanto, para sustentar minha apresentação, busco o conceito de biblioteca pública definido pela Unesco, em seu Manifesto, e que serve de apoio às instituições nacionais e internacionais:

A biblioteca pública é o centro local de informação, tornando prontamente acessível aos seus utilizadores o conhecimento e a informação de todos os gêneros. Os serviços da biblioteca pública devem ser oferecidos com base na igualdade de acesso para todos, sem distinção de idade, raça, sexo religião, nacionalidade, língua ou condição social. Todos os grupos etários devem encontrar documentos adequados às suas necessidades. As coleções e serviços devem incluir todos os tipos de suporte e tecnologias modernas apropriadas assim como materiais tradicionais. É essencial que sejam de elevada qualidade e adequadas às necessidades e condições locais. e devem refletir as tendências atuais e a evolução da sociedade, bem como a memória da humanidade e o produto da sua imaginação. As coleções e os serviços devem ser isentos de qualquer forma de censura ideológica, política ou religiosa e de pressões comerciais (UNESCO, 1994, p. 1).

Ao elaborar o Manifesto, a Unesco propõe que a biblioteca pública seja um espaço democrático, com livre acesso ao conhecimento, à cultura e informação possibilitando assim o desenvolvimento sociocultural e econômico da sociedade.

Nesta perspectiva avalia-se que, em nosso país, há carências de serviços de bibliotecas públicas. Predomina-se ainda a desigualdade social e cultural, pela falta de recursos orçamentários destinados aos estados e municípios, com vistas a estabelecer políticas públicas que corrobore de forma efetiva com um plano nacional para as bibliotecas.

Ressalta-se ainda o surgimento das bibliotecas comunitárias criadas por iniciativa popular, o que evidencia a falta desses espaços culturais nas comunidades. Assim, igrejas, associações de bairros, movimentos populares abrigam em suas ações o papel destinado às bibliotecas públicas, de responsabilidade dos governos. Atualmente, são tantas as iniciativas que o PNLL - Plano Nacional do Livro e da Leitura abre todos os anos, edital público para fortalecimento das ações realizadas pelas bibliotecas comunitárias. Não há demérito na ação, visto que tem contribuído com a promoção da leitura entre as camadas populares, entretanto os municípios ficam alheios às iniciativas o que muitas vezes compromete os serviços. Sabemos que há um esforço do governo, instituído por meio da Fundação Biblioteca Nacional, em estabelecer 
políticas para a área do livro, da leitura e das bibliotecas, mas inexiste mecanismo que exija o cumprimento pelos estados e municípios, fato que termina por fragilizar e dificultar a viabilidade das políticas propostas.

\section{Contextualizando o projeto das Bibliotecas Públicas em Caparaó}

O projeto "Educação Ambiental em Caparaó: uma proposta de construção de uma comunidade de aprendizagem" desenvolveu ações nas áreas de: Memória Histórica, Educação, Saúde, Meio Ambiente e Formação de Grupo envolvendo as comunidades de Caparaó e Alto Caparaó.

Em 1994 o Encontro Municipal de Educação de Caparaó e, em 1997 a I Conferência Municipal de Educação de Alto Caparaó, reforçou a proposta de criação de uma biblioteca local, como reivindicação dos municípios.

Nesse contexto, ocorreu também a realização de cursos de capacitação para professores, o intercâmbio cultural entre alunos do Coltec/UFMG e alunos dos municípios envolvidos; os programas da área da saúde; a formação do grupo de astronomia, dentre outras ações, colocaram em evidência a falta de infraestrutura informacional. A inexistência de biblioteca trouxe uma inquietação em relação ao processo de aprendizagem. Nesta perspectiva e com objetivo de garantir material para dar suporte aos cursos oferecidos nas diversas áreas promovidos pelo projeto, à proposta de implantação de bibliotecas públicas foi inserida no projeto apresentado à Fundação W.K. Kellogg.

O processo de implantação teve início em 1999 e foi concluído em 2005, com a apresentação de um relatório final.

Envolver as comunidades no processo foi uma das primeiras ações. Um pequeno questionário foi desenvolvido com a finalidade de conhecer a comunidade e inserir o conceito de biblioteca entre eles.

A etapa seguinte foi organizar uma programação com visita cultural às instituições em Belo Horizonte (bibliotecas públicas, escolares, universitárias, museus e livrarias). O objetivo era apresentar os vários tipos de instituições culturais para a formação do conceito "biblioteca pública".

A partir daí formou-se uma comissão, em cada município, para participar do processo de seleção do acervo. Representantes de instituições como Emater, Parque Nacional do Caparaó também foram convidados a participar do processo. Foi necessário o contato com editoras e distribuidoras para o fornecimento de obras que atendessem as várias áreas. Este processo foi riquíssimo em termos de conhecimento e valorização do acervo. Cada município compôs a sua lista e isto ficou evidente no momento da aquisição. Em um dos municípios a área de educação foi predominante, com a maioria dos livros para suporte aos professores, enquanto o outro priorizou a literatura. A aquisição de filmes e cds, além de assinatura de um jornal e revistas para o publico adulto e 
infantil. O acervo para a brinquedoteca também ganhou espaço no projeto.

Uma equipe de arquitetos, alunos da UFMG, elaborou o projeto de construção e acompanhou todo o processo. Os municípios foram responsáveis pela liberação dos recursos para edificação do espaço.

A formação e capacitação de jovens no curso de contadores de histórias, em Caparaó, deu origem ao Grupo Igapara, que durante cerca de cinco anos realizaram atividades literárias, com saraus, exposições, encontros culturais na Biblioteca Pública.

Para envolver a comunidade, antes da inauguração das bibliotecas, foram programadas atividades culturais em vários momentos aproximando assim o público potencial. Os contadores de histórias, as atividades literárias nas escolas foram alternativas encontradas.

\section{A inauguração das bibliotecas}

A Biblioteca Pública Municipal Rejane de Araújo, no Alto Caparaó a e Biblioteca Municipal Prefeito Antônio Xavier da Costa, no município de Caparaó foram inauguradas em dezembro de 2001.

Com espaço físico bem planejado, mobiliário, equipamentos e acervo com aproximadamente 3.000 títulos destinado ao público adulto e infantil, além de revistas e um jornal diário, uma brinquedoteca para os pequeninos conseguiu atrair um público significativo. A chegada da Biblioteca Pública trouxe para a comunidade uma dimensão mais cultural para cerca de 4.000 habitantes, em cada município.

Com um espaço diferenciado e sendo novidade entre os moradores as bibliotecas tornaram-se locais para encontros, saraus, apresentação do coral, atividades literárias com contadores de histórias, a leitura poética, exposições e até mesmo recepção de turistas do Parque Nacional de Caparaó.

Para os gestores públicos que, a princípio, consideravam que o espaço projetado para as bibliotecas ultrapassavam a necessidade da comunidade a frequência acabou por desmistificar a visão simplista e fortaleceu a iniciativa para ampliar o atendimento às comunidades rurais.

\section{Ampliando as ações}

Os dois municípios contam com uma parcela significativa de moradores na zona rural, em função da sua economia baseada na agricultura do café. Isto trouxe para o coordenador do projeto um motivo a mais para apresentar à W.K. Kellogg um projeto para ampliação dos serviços das bibliotecas. Nesta perspectiva surge um segundo projeto de leitura.

A proposta de "Implantação de um serviço de extensão da Biblioteca Pública Municipal - Biblioteca Móvel - para os moradores da área rural de Caparaó", sua consolidação ocorreu em 2004, tendo como objetivo de ampliar as ações das bibliotecas. E foi realizado em quatro etapas: 
a)Aquisição de um carro, modelo Kombi e dezesseis baús,

b)Seleção e aquisição de cerca de 250 títulos (entre livros e revistas para crianças, jovens e adultos);

c)Realização de cursos de capacitação para moradores das dezesseis comunidades, que se dispusera a receber o baú de livros;

d)Distribuição e entrega dos baús nas comunidades rurais

. O processo de implantação dos baús a exemplo das bibliotecas também envolveu a comunidade rural. Com encontros locais para falar dos objetivos da ação e sua importância em levar leitura para crianças, jovens, adultos. O valor da informação para homens e mulheres plantadores de café, selecionando textos direcionados ao seu cotidiano, além de obras literárias foram motivos para reunir novamente a comissão de seleção.

No projeto a função da Kombi era de propiciar a entrega dos baús nas comunidades e levar pessoal para atividades culturais como: grupo de contadores de histórias, coordenadores locais para visitar as comunidades e efetivar o acompanhamento do projeto.

O desafio entretanto era definir um local onde instalar o baú e propiciar o empréstimo de livros e revistas. A escolha de um morador "voluntário" que disponibilizasse um espaço para sua guarda e recebesse a comunidade foi superado. O compromisso de oferecer cursos para funcionamento da proposta possibilitou a definição de pessoas nas várias comunidades.

No município de Caparaó foram distribuídos treze baús e outros três em Alto Caparaó. O acervo de cada baú contava com cerca de até 108 livros, 16 revistas e 20 folhetos com temáticas diversificadas. Os folhetos informativos, principalmente os da EMATER, foram selecionados como fonte de circulação da informação entre os agricultores. Quanto aos livros a proposta de acervo diversificado para permitir o rodízio dos baús e com isto ampliar as possibilidades de leitura foi bem aceita.

Alguns depoimentos demonstram como o projeto de extensão, através dos baús, aconteceu nas comunidades e apontam, nas falas, o sucesso e as dificuldades encontradas: ${ }^{2}$

" Foi melhor na casa. Na escola os meninos mexem muito, $\mathrm{Na}$ escola tem também a questão do horário. Aqui, Luana agora atende todas as vezes que as crianças procuram" (Luciléia e Luana).

"Incentivam mais pessoa a procurarem os livros para ler, independente de estar na escola ou não. Ajuda na questão de

\footnotetext{
${ }^{2}$ Depoimentos dos participantes do projeto Implantação de um serviço de extensão da Biblioteca Municipal Bibliotec Móvel - para os moradores da zona rural de Caparaó/Minas Gerais - Brasil.
} 
outros horários diferentes da escola" (Daniela, Laís, Sara, Débora, Lidiane e Natália).

"Não está tendo muito movimento, não sei se é pela época da apanha (início em junho/julho). Estou fazendo muita propaganda" (Roseni e Nayara).

"No ponto de vista estou achando muito bom. Incentiva os meus alunos a lerem. Estou gostando, nunca tinha participado desse processo de voluntariado. Ajuda muito na reflexão vendo a importância para a comunidade, pois o voluntário não faz isto por obrigação,mas sim com prazer em ajudar outras pessoas" (Cristiane).

"Uma experiência nova que a gente ganha. Tenho um outro tipo de movimento que não seja só com panelas e fogão. A gente comunica com outras pessoas" (Inêz).

"No começo foi mais impolgante (curiosos ver a coleção). O período de apanha atrapalhou um pouco, as pessoas chegam cansadas do trabalho. É difícil. A comunidade fica na apanha entre abril e setembro. Até na igreja a frequencia é menor" (Aparecida).

"Poucos estão vindo, só isso. Têm gostado, agradam dos livros. Um senhor perguntou se tinha alguma coisa sobre abelhas. Olhei no baú. Achei e emprestei. Procurei saber se valeu e ele falou que valeu muito. Que era aquilo que ele precisava" (Roseni)

"São aproximadamente 14 famílias que moram na comunidade. Acho que as questões políticas atrapalham um pouco" (Cristiane).

"As crianças da turma da terceira série têm um caderno de literatura para anotar biografias dos autores, resumo do livro (o que entenderam), sobre os livros de imagem fazem sua leitura. Muitas vezes as crianças querem ler o mesmo livro. Por causa da capa. No longe das gerais, por causa das ilustrações. Os dez sacizinhos muito procurado por causa das ilustrações. Algumas crianças levam revistas para a mãe ler (culinária). Folhetos da EMATER quando as crianças gostam muito da agricultura, a Revista Sitio. A percepção é que as crianças têm melhorado a oraliade (leitura mais fluente) caso dos irmãos. Um livro de química (pertencente ao acervo) ajudou uma das volutárias a tirar dúvidas que tinha" (Laís, Daniela, Sara, Débora, Lidiane, Natália).

"Teve mulheres, principalmente, procurando revistas de crochê e vagonite. As revistas sobre lavouras são as mais procuradas. Comentário: Contou história na catequese (achou diferente). Percebe que melhorou depois que fez o curso. 
Perdeu o medo de falar em público, melhorou a forma de contar. Comentou também que os pais falam que as crianças agora ao invés de ver televisão, ficam mais lendo os livros que levam" (Danieli)

Todo esse material apresentado no Informe Narrativo - final (01/07/2004 a 31/09/2005) e enviado a W.F. Kellogg foi encaminhado aos municípios para conhecimento e divulgação. Entretanto, isto não impediu que os baús fossem recolhidos., o que demonstra a falta de compromisso com o investimento da Fundação W.K. Kellogg e da UFMG e com a população local o que mostra o quanto as autoridades e gestores estão alheios ao desenvolvimento de seus municípios.

O acompanhamento das ações de implantação das bibliotecas e do serviço de extensão encerrou em 2005, com visitas e reuniões nas comunidades.

\section{Revisitando as bibliotecas de Caparaó e Alto Caparaó}

No intuito de apresentar, no Seminário, um quadro real das bibliotecas públicas e analisar fatores que contribuem para melhoria ou ineficácia dos serviços, propus uma agenda de visita aos municípios, em outubro de 2013, isto é, doze anos após a inauguração das bibliotecas públicas.

Revisitar as bibliotecas, conversar com a equipe de funcionários, visitar as bibliotecas das escolas e conversar com professores, além de entrevistar os secretários de educação e cultura dos municípios foi a meta proposta para verificar avanços e retrocessos

Os resultados das visitas, das entrevistas informais e percepção das dificuldades enfrentadas diferenciaram entre os municípios e merecem destaque:

A gestão pública

1)Os secretários confirmaram o não repasse de verbas ou qualquer outro tipo de apoio nestes anos, alegando dificuldades do município. Apenas um dos secretários ocupa o cargo há menos de quatro anos;

2)Falta manutenção nos prédios e também nos equipamentos. A Biblioteca Pública de Alto Caparaó está com as paredes comprometidas por infiltração. Na área externa destinada a atividades culturais foi construída uma sala para abrigar a Sala de Inclusão Digital e que, segundo as funcionárias da biblioteca, funcionou pouco tempo e há mais de um ano está fechada. O espaço da brinquedoteca está em péssimas condições de funcionamento; 
3)A biblioteca, do município de Caparaó, está com seu espaço físico menos comprometido, mas precisando também de reforma, pintura.Um projeto para readequação do espaço utilizado pela brinquedoteca foi apresentado à administração municipal;

4)A renovação de assinaturas de revistas e jornais e a aquisição de livros, não foram feitas desde a implantação da Biblioteca Municipal de Alto Caparaó;

5)No município de Caparaó a renovação de revistas e jornais foi feita durante um período. E a aquisição de livros não aconteceu nestes doze anos;

6)Há mais de oito anos não é realizado cursos de capacitação, somente aqueles oferecidos pelo Projeto;

7)Mesmo com a criação do Conselho Municipal de Cultura, em Alto Caparaó, com aprovação de repasse de verba do orçamento municipal, a Biblioteca Pública, ainda não usufruiu deste benefício;

Em relação ao serviço de extensão por meio da "Biblioteca Móvel" constatou-se que:

1)Em Caparaó as atividades foram encerradas há mais de três anos, com recolhimento dos baús, houve perda de parte do acervo, e a Kombi que servia de suporte ao projeto está completamente danificada;

2)No município de Alto Caparaó apenas uma comunidade continua com o baú de livros funcionando. A duas outras comunidades que tiveram as escolas rurais fechadas, os acervos foram incorporados ao das escolas municipais, na área urbana.

Vale ressaltar que as bibliotecas das escolas municipais e da estadual estão com seus acervos diversificados, de excelente qualidade e bem organizados, situação oposta à época da implantação das bibliotecas públicas. Segundo professores que atuam nas bibliotecas, as escolas recebem livros do Governo, além de participarem de projetos do Ministério da Educação, o que contribui com atualização e melhoria do acervo.

Outro ponto de destaque foi constatar a realização de ações de leitura envolvendo a biblioteca da escola. Nas falas de professores e dos responsáveis pela biblioteca a mudança foi motivada a partir das dificuldades encontradas na relação com a Biblioteca Pública. Na época da inauguração as escolas eram convidadas a levarem os alunos para as atividades, ou, um funcionário deslocava-se até a escola para realizar atividades. A justificativa apresentada pela equipe é que houve redução no quadro de pessoal nas Bibliotecas Públicas. Em Caparaó ainda acontece parceria com escolas, uma forma de preservar a imagem de "biblioteca 
referência" entre os municípios do entorno, que serve como relevância para os funcionários.

\section{Considerações e desafios}

Mesmo não atuando profissionalmente acompanho as ações em torno da leitura e da biblioteca. É importante que os municípios participem das ações e projetos de incentivo à leitura, propostos pelo Governo. Há programas e planos criados pelo Minc e desenvolvidos pela Fundação Biblioteca Nacional que apontam uma perspectiva de melhoria para as bibliotecas públicas e consequente avanço nas questões da leitura.

A pesquisa publicada em "Retratos da leitura no Brasil" (2008), confirma que o brasileiro ainda lê pouco, apesar dos programas de governo para zerar o número de municípios brasileiros sem biblioteca. Há também os programas de distribuição de livros e de formação de mediadores de leitura, que a médio e longo prazos deverão oferecer resultados positivos. Entretanto, é preciso identificar ações que promovam a leitura para além do espaço escolar, visto que os dados da pesquisa apontam que o número de pessoas que acreditam que leitura é importante, apenas no período da escola apresentou um percentual elevado.

A pesquisa revela também que entre os entrevistados que fizeram ou fazem cursos universitários, o número de leitores é significativo, mas na parcela de adultos que não estudam constata-se que os indicadores de leitura decrescem, o que faz crer que a escola não tem formado leitores para a vida toda, segundo seus analisadores.

A edição de 2011 aponta avanços em relação à edição anterior, mas os indicadores de leitura apresentaram resultados inferiores em relação a 2007; apenas na região nordeste o índice ultrapassou os de 2007 o que, segundo os analisadores, é reflexo do aumento de pessoas que voltaram a estudar.

Outro aspecto importante é a necessidade de reflexão sobre a descontinuidade dos programas governamentais ou institucionais em relação a;

a)Falta de dotação orçamentária para execução e continuidade das ações;

b)Necessidade de avaliação criteriosa dos resultados antes da interrupção dos programas e ações;

c)Promoção de debates periódicos para atualização de profissionais que atuam na área;

d)Sistematização e divulgação de dados relativos às ações e programas desenvolvidos;

e)Valorização da biblioteca pública enquanto instituição de promoção do desenvolvimento humano e social; 
f)Falta de compromisso político dos governantes, gestores, administradores com a área cultural.

Todos estes fatores, se não atendidos, comprometem as ações e muitas vezes contribuem com a extinção de programas consolidados.

A fala dos secretários, dos municípios de Alto Caparaó e Caparaó, exemplifica bem a falta de compromisso com as bibliotecas e com os profissionais que nelas atuam. A biblioteca do município deve ser vista pelo poder público como uma instituição inspiradora do desenvolvimento e não um peso para os cofres públicos.

É importante que a equipe da biblioteca pública envolva a comunidade em suas ações, afinal a sua existência só se justifica em função dos serviços oferecidos aos seus leitores, como diz o Manifesto da IFLA/UNESCO.

A alegação de orçamento insuficiente, por parte de gestores do município, para atender a área cultural é comum, mas improcedente. 0 argumento pode ser verdadeiro, mas injustificável se a cada ano fosse priorizado um aspecto da manutenção ou melhoria dos serviços da biblioteca.

Estes dados e informações só reforçam o quanto a leitura precisa ser respirada entre nós brasileiros, o quanto precisamos de profissionais preocupados e ao mesmo tempo comprometidos com a melhoria dos indicadores de leitura.

Merecem aplausos àqueles que fazem da leitura um momento de vida e acreditam em seu potencial para o desenvolvimento pleno, a exemplo do Prof. Marcos Nicácio com sua fidelidade ao projeto das bibliotecas apesar dos entraves apontados.

\section{Referências}

AMORIM, Galeno (Org.). Retratos de Leitura no Brasil. São Paulo: Imprensa Oficial: Instituto Pró-Livro, 2008.

BIBLIOTECA PUBLICA MUNICIPAL DE CAPARAÓ. Implantação de um serviço de extensão da Biblioteca Municipal - Bibliotec Móvel - para os moradores da zona rural de Caparaó/Minas Gerais - Brasil. Informe Narrativo Final, 10 jul. 2004 a 31set. 2005.

CESARINO, Maria Augusta Nóbrega (Org.). Biblioteca Pública Estadual Luiz de Bessa: 50 anos de cultura. Belo Horizonte: Secretaria de Estado de Cultura de Minas Gerais/Superintendência de Bibliotecas Públicas, 2006.

DUARTE, Adriana Bogliolo Sirihal; LOURENÇO, Cintia de Azevedo (Org.). 0 Carro-Biblioteca da ECI/UFMG: 38 anos. Belo Horizonte: Rona Editora, 2012.

FAILLA, Zoara (Org.). Retratos de Leitura no Brasil 3. São Paulo; Instituto Pró-Livro, 2012. Disponível em: <http://www.prolivro.org.br/images/antigo/4095.pdf >. Acesso em: 14 ago. 2014. 
MINAS GERAIS. Serviço Social do Comércio - SESC (Org.). Pelos Caminhos das Gerais: unidades volantes e projetos itinerantes. Belo Horizonte: SESC/MG, 2008.

REIS, Alcenir Soares; REZENDE, M.E.P. Escutando a comunidade: em discussão a extensão junto a camadas populares. Revista da Escola de Bibliotecomia da UFMG, Belo Horizonte, v. 24, n. 2, p. 289-312, jul./dez. 1995.

UNESCO. Manifesto IFLA/UNESCO sobre bibliotecas públicas. 1994. Disponível em: <http://archive.ifla.org/VII/s8/unesco/port.htm>. Acesso em: 21 set. 2013. 